\title{
Endothelial CXCL12 regulates neovascularization during tissue repair and tumor progression
}

\section{Authors}

Zeshaan N. Maan, MD, MSc, MRCS ${ }^{1}$, Michael S. Hu, MD, MPH, MS ${ }^{1} \uparrow$, Robert Rennert, MD ${ }^{1} \uparrow$, Janos A. Barrera, $\mathrm{MD}^{1}$, Dominik Duscher, $\mathrm{MD}^{1}$, Michael Januszyk, $\mathrm{MD}, \mathrm{PhD}^{1}$, Alexander Whittam, $\mathrm{BA}^{1}$, Jagannath Padmanabhan $\mathrm{PhD}^{1}$, Nicholas Vial, $\mathrm{MD}^{1}$, Natalie $\mathrm{Ho}^{1}$, Lauren $\mathrm{H}$. Fischer, $\mathrm{MD}^{1}$, Johannes Riegler, $\mathrm{PhD}^{2}$, Joseph C. Wu, MD, $\mathrm{PhD}^{2}$, Michael T. Longaker, MD, MBA ${ }^{1}$, Geoffrey C. Gurtner, MD, FACS $^{1 *}$

$\dagger$ These authors contributed equally to this work.

\section{Affiliations}

${ }^{1}$ Department of Surgery, Division of Plastic and Reconstructive Surgery, Stanford University School of Medicine, Stanford, California, USA

${ }^{2}$ Stanford Cardiovascular Institute, Stanford University School of Medicine, Stanford, California, USA

Short Title: Endothelial cell CXCL12 regulates tissue repair

\section{*Corresponding Author:}

Geoffrey C. Gurtner, MD, FACS

Professor and Associate Chairman of Surgery

Stanford University School of Medicine

Department of Surgery, Division of Plastic and Reconstructive Surgery

257 Campus Drive West, Hagey building GK-201

Stanford, CA 94305-5148

Phone: (650) 724 - 6672

Fax: (650) 724 - 9501

E-mail: ggurtner@stanford.edu 


\section{Abstract}

CXC chemokine ligand 12 (CXCL12; stromal cell-derived factor 1 [SDF-1]), primarily known for its role in embryogenesis and hematopoiesis, has also been implicated in tumor biology and neovascularization. However, its specific role and mechanism of action remain poorly understood. We previously demonstrated that CXCL12 expression is Hypoxia-Inducible Factor (HIF)-1 responsive. Here we use a conditional CXCL12 knockout mouse to show that endothelial-specific deletion of CXCL12 (eKO) does not affect embryogenesis, but reduces the survival of ischemic tissue, altering tissue repair and tumor progression. Loss of vascular endothelial CXCL12 disrupts endothelial - fibroblast crosstalk necessary for stromal growth and vascularization. Single-cell gene expression analysis in combination with a parabiosis model reveals a specific population of non-inflammatory circulating cells, defined by genes regulating neovascularization, which is recruited by endothelial CXCL12. These findings indicate an essential role for endothelial CXCL12 expression during the adult neovascular response in tissue injury and tumor progression. 


\section{Introduction}

Adult neovascularization (new blood vessel growth in response to ischemia) plays a crucial role in tissue repair and regeneration and influences functional outcomes after injury to the heart, brain, and periphery . The complex biological processes governing neovascularization and tissue repair are exploited by tumor cells (Carmeliet et al., 2011; Hanahan et al., 2011), which typically exist in a setting of relative ischemia (Helmlinger et al., 1997). It is increasingly apparent that tumor survival and progression critically relies on the stromal microenvironment (Li et al., 2003). While numerous studies have explored the importance of a vascularized stroma to both physiologic tissue repair and pathologic tumor development (Valkenburg et al., 2018), an insufficient understanding of the underlying molecular mechanisms has limited the development of effective therapeutics to target this process.

Our laboratory and others have previously described the pivotal role of Chemokine (C-X-C motif) ligand 12 (CXCL12) in the recruitment of circulating cells to hypoxic tissue, secondary to stabilization of Hypoxia-Inducible Factor (HIF)-1 (Ceradini et al., n.d.), and regulation of stem cell microenvironments (Ding et al., 2013; Greenbaum et al., 2013). Interestingly, CXCL12 is also widely expressed in a number of human tumors and has a role in tumor progression and survival (Feig et al., 2013; Orimo et al., 2005; Teicher et al., 2010). These reports suggest a critical role for CXCL12 in both tissue repair and tumor progression, two physiological processes that depend on a delicate orchestration of molecular and cellular factors that govern neovascularization. The mechanisms underlying the influence of CXCL12 on these seemingly disparate processes remains unknown. We hypothesized that interrogating the role of CXCL12 in neovascularization would provide an opportunity to unravel the complex molecular mechanisms that underlie these processes. 
Here we use a conditional CXCL12 knockout mouse to identify a critical role for vascular endothelial specific CXCL12 expression in neovascularization and tumor progression. Knockout of endothelialspecific CXCL12 inhibits wound healing and ischemic tissue survival. Surprisingly, loss of endothelial CXCL12 expression completely abrogates tumor growth despite high levels of continued CXCL12 expression by both tumor cells and tumor-associated fibroblasts. We demonstrate that loss of endothelial CXCL12 inhibits fibroblast proliferation, survival, and expression of angiogenic cytokines, clarifying the importance of endothelial-fibroblast cross-talk in this process. Finally, utilizing single-cell gene expression analyses in combination with a parabiosis model, we identify a non-inflammatory progenitor cell subpopulation exclusively recruited to tissue by endothelial CXCL12 signaling. These data reveal a crucial role for vascular endothelial-derived CXCL12 in both tissue repair and tumor progression and uncover a paracrine mechanism governing the formation of vascularized stroma. 
9 0

\section{Results}

Vascular endothelial derived CXCL12 does not regulate embryogenesis or vasculogenesis

To specifically assess the role of endothelial CXCL12 during neovascularization, we engineered a floxed allele of $\operatorname{Cxcl12}$ (Cxcl12 loxP/loxP $)$ (Figure 1A). Rosa-creER and Tie2-cre transgenes were utilized to generate tamoxifen-inducible global CXCL12 knockout (gKO) and endothelial-cell-specific (Ding et al., 2013; Greenbaum et al., 2013; Kisanuki et al., 2001) CXCL12 knockout (eKO) mice (Figure 1B), respectively. CXCL12 knockout progeny (CXCL12 loxP/loxP; ROSA-creER ${ }^{+/-}$, Tie2-cre $\left.{ }^{+/-}\right)$were viable, fertile, produced at expected Mendelian ratios and showed no overt pathologic phenotype. We confirmed DNA recombination upon tamoxifen administration with a subsequent $>80 \%$ decrease in mRNA and protein expression of CXCL12 (Figure 1C-E). Endothelial specific knockout of CXCL12 was additionally validated used immunostaining (Figure 1F). Prior work has demonstrated that stromal expression of CXCL12 is critical during embryogenesis (Nagasawa et al., 1996), cardiac development (Nagasawa et al., 1996; Tachibana et al., 1998), hematopoiesis (Nagasawa et al., 1996), and organ vascularization (Tachibana et al., 1998). Immunostaining and standard histology were utilized to examine organ development and vascularization in eKO mice and demonstrated normal morphology and vascular pattern (Supplementary Figure 1). This suggests that endothelial CXCL12 does not have a primary role during organogenesis and vascular development.

(1)

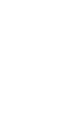

(3)


bioRxiv preprint doi: https://doi.org/10.1101/2020.05.24.113845; this version posted May 27, 2020. The copyright holder for this preprint (which was not certified by peer review) is the author/funder, who has granted bioRxiv a license to display the preprint in perpetuity. It is made available under aCC-BY-NC-ND 4.0 International license.

A

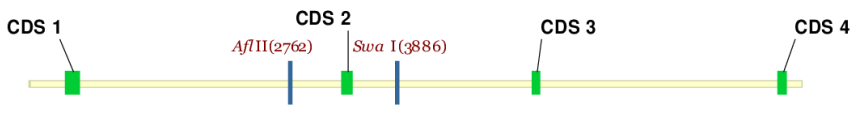

Construct

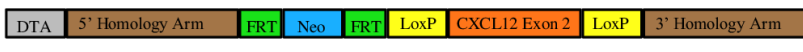

Genome placement confirmed by southern

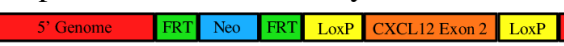

FRT removal confirmed by PCR

Exon removal confirmed in ES cells by PCR.

\section{[FRT LoxP}

\section{B}

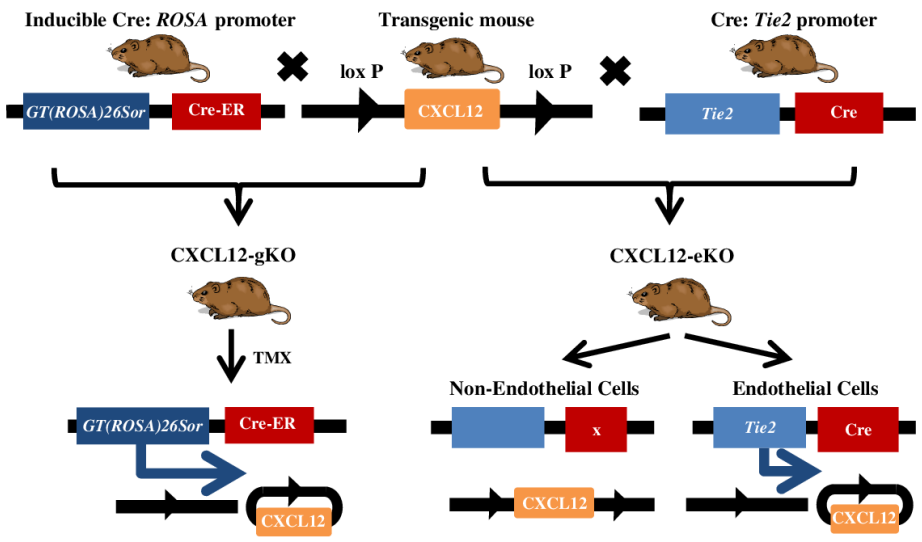

C

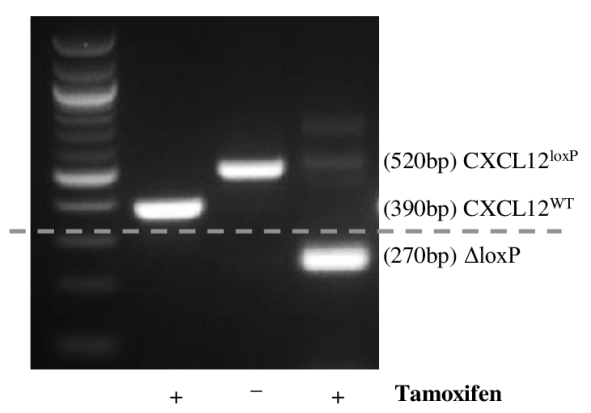

D

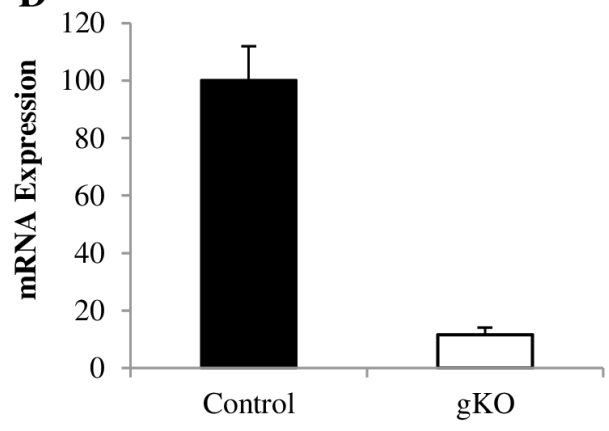

$\mathbf{E}$

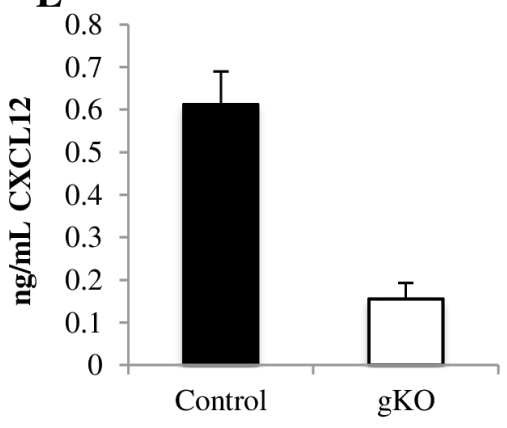

F

Skin

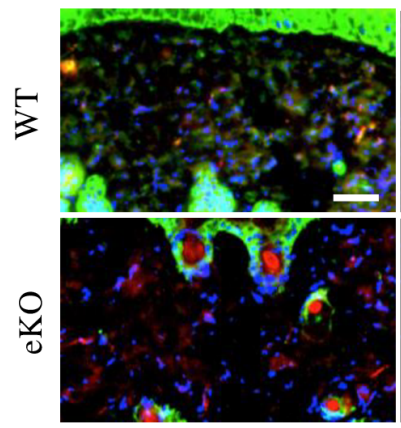

Brain

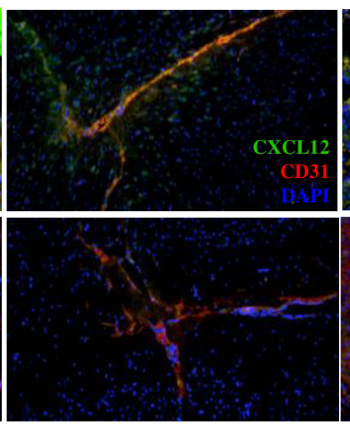

Lung
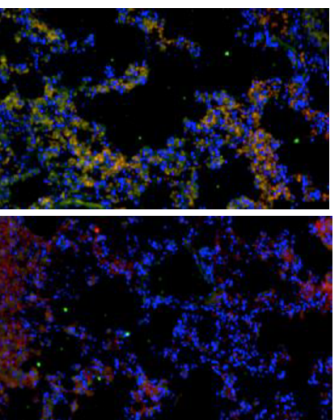

Heart
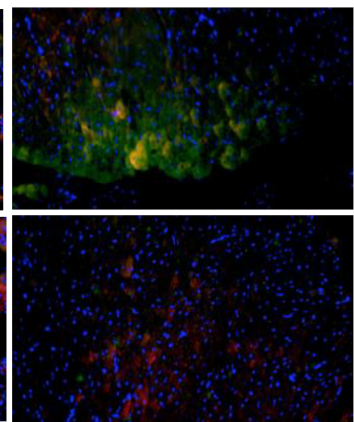

Stomach

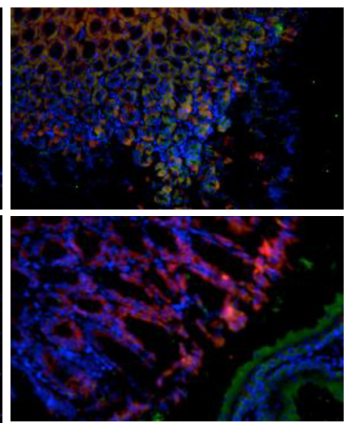


117 Figure 1. Development and validation of gKO and eKO CXCL12 mice.

118 (A) Schematic of the murine Cxcl12 locus depicting our approach to homologous recombination in

119 embryonic stem cells to generate a floxed Cxcl12 allele. Cxcl12 floxed mice were crossed with mice

120 carrying the Cre-recombinase transgene to generate tissue-specific knockout progeny) (B) Schematic of

121 the breeding strategy used to generate tamoxifen inducible global Cxcl12 knockout (gKO) and

122 endothelial-cell specific Cxcl12 knockout (eKO) mice. (C) PCR validation of the presence and

123 recombination of the floxed allele upon exposure of gKO mice to tamoxifen. (D) qRT-PCR of Cxcl12

124 expression in the skin of tamoxifen induced gKO mice compared to control. (E) ELISA for Cxcl12 levels

125 in the skin of tamoxifen induced gKO mice compared to control. (F) Immunohistochemical analysis

126 showing overlapping expression of CXCL12 and CD31 in wild type but not eKO mice. Images obtained

127 with a Zeiss Axioplan 2 fluorescence microscope, magnification x20, scale bar $200 \mu \mathrm{m}$. 
Vascular endothelial CXCL12 critically regulates neovascularization and tissue repair.

132 We then investigated the role of CXCL12 in adult tissue repair using an excisional cutaneous injury model

133 in eKO and gKO mice (Galiano et al., 2004). We found that both eKO and gKO mice showed delayed

134 healing of their wounds compared to floxed control mice (16 days vs. 11 days, respectively) (Figure 2A, B). The impairment in tissue repair in both knockout groups was apparent by the 4th day after injury, as measured by remaining wounded area (Figure $2 \mathrm{C}$ ). The similar healing times of eKO and gKO mice (Figure 2A-C) suggests that endothelial cells are the critical source of CXCL12 during the repair of injured tissue in adults. Microscopically, the most obvious difference in the healed tissue of eKO mice was a decreased vascular density by immunostaining (Figure 2D, E). We analyzed the injured tissue at earlier time points and found reduced transcription and protein expression of CXCL12 in eKO mice. In addition,

141 VEGF and FGF-2 transcription and protein expression were diminished (Figure 2F-H), suggesting that the CXCL12 signaling modulates other HIF-1 regulated, angiogenic signaling pathways. To confirm the critical role of endothelial CXCL12 signaling during neovascularization, we used a dorsal ischemic skin flap model (Ceradini et al., n.d.), which demonstrated decreased tissue survival in eKO versus wild type mice (Figure 3A-D). Similarly, using a myocardial ischemia model (Patten et al., 1998), in which the left 
bioRxiv preprint doi: https://doi.org/10.1101/2020.05.24.113845; this version posted May 27, 2020. The copyright holder for this preprint (which

was not certified by peer review) is the author/funder, who has granted bioRxiv a license to display the preprint in perpetuity. It is made available under aCC-BY-NC-ND 4.0 International license.

A

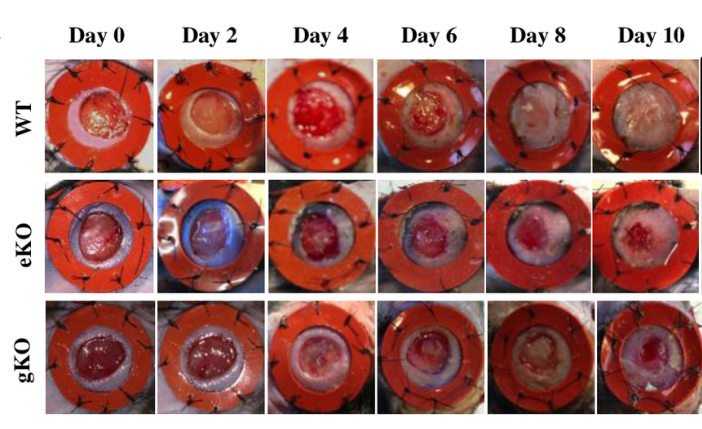

C
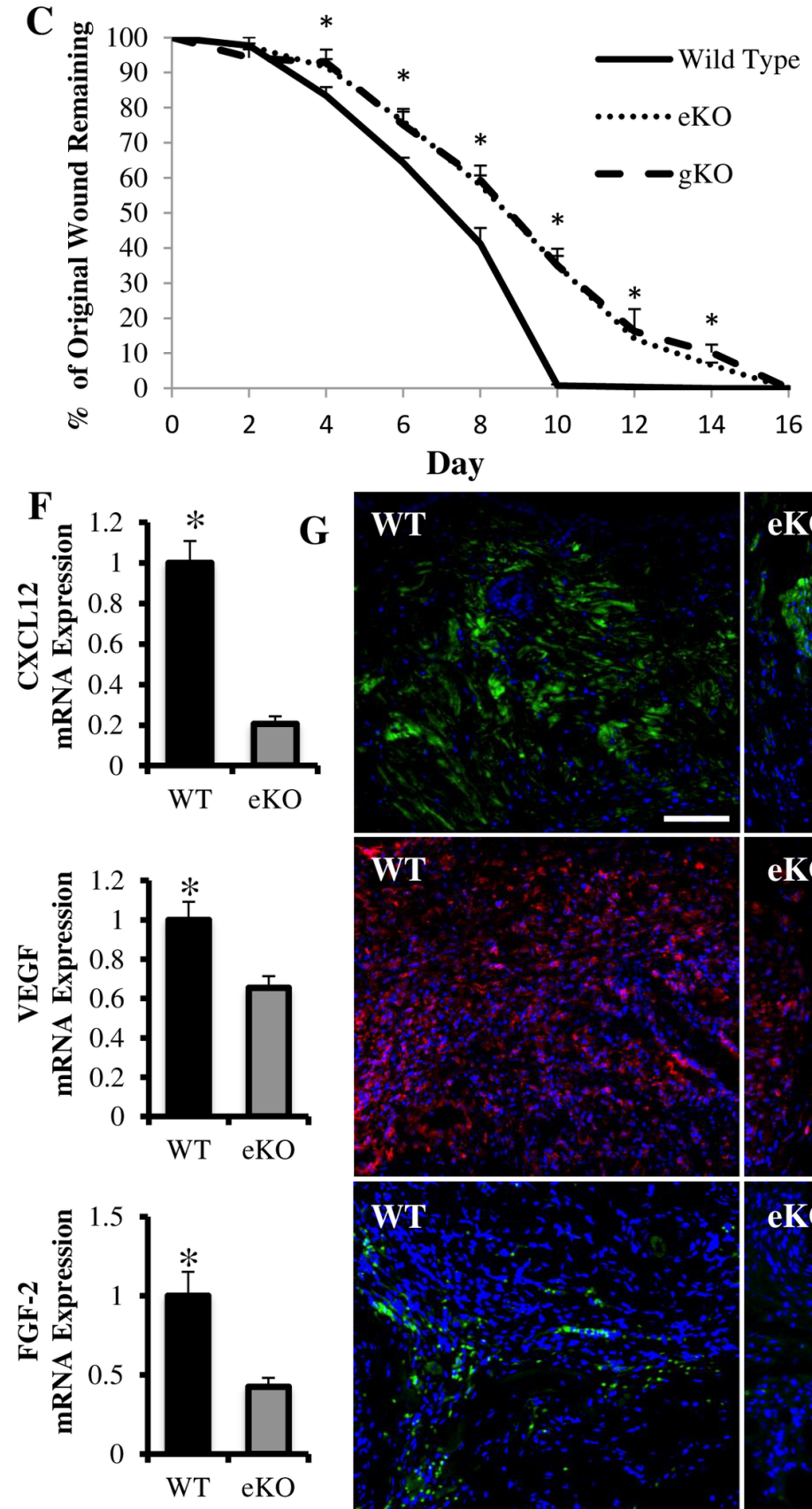

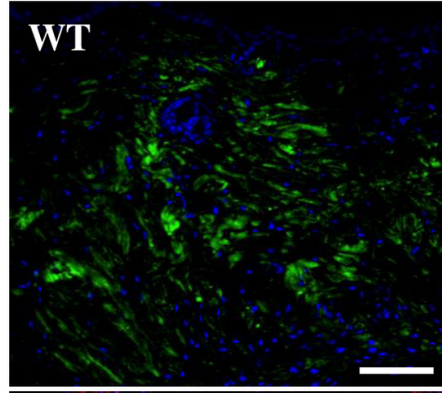

eKO

D
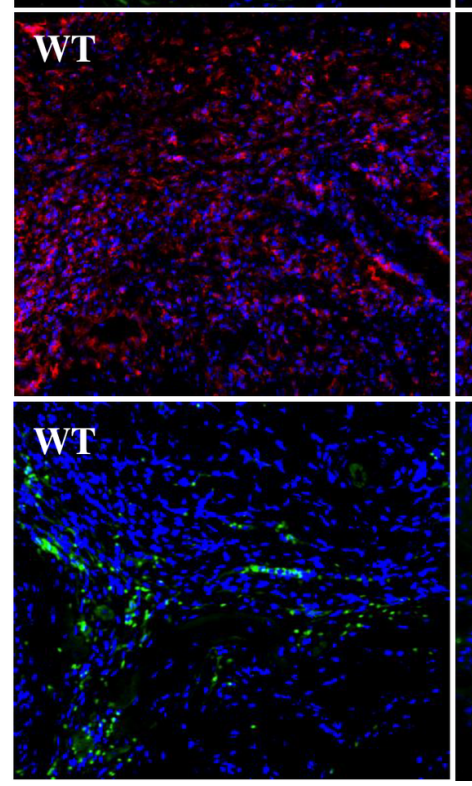
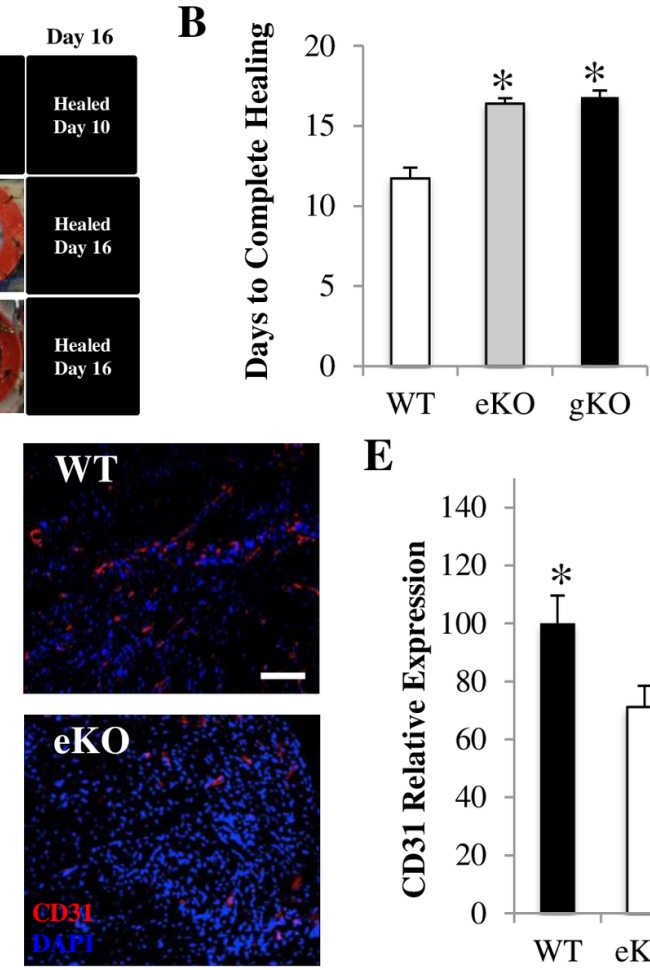

E

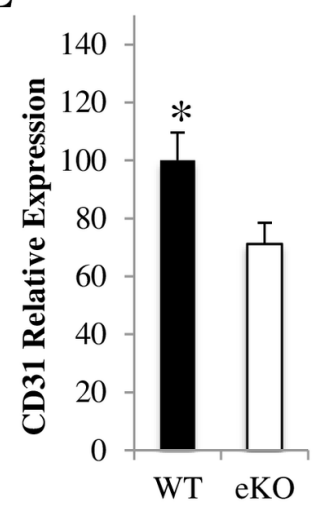

'CXCL12

eKO

VEGF
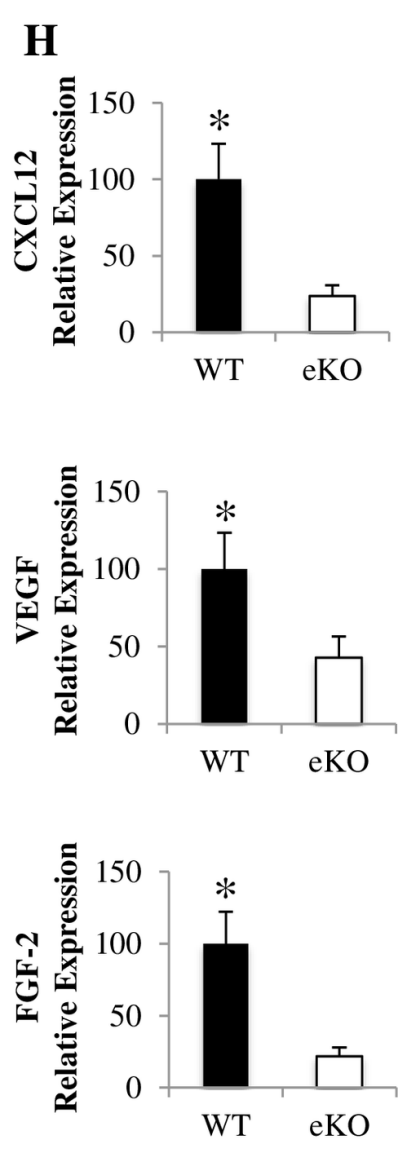


\section{Figure 2. Wound healing relies on endothelial CXCL12.}

149 (A) Representative images of similarly delayed healing in endothelial specific (eKO) and global CXCL12

150 knockout $(\mathrm{gKO})$ mice compared to wild type (WT). $(\mathrm{B}, \mathrm{C})$ Both eKO and gKO mice require 16 days to

151 heal compared to 11 days in control. (D, E) Decreased vascular density in fully healed wounds of eKO

152 mice. Images obtained with a Zeiss Axioplan 2 fluorescence microscope, magnification x20, scale bar 200

$153 \mu \mathrm{m}$. (F) Decreased expression of Ccxl12 (top), Vegf (middle), and Fgf2 (bottom) in the wounds of eKO

154 mice. (G, H) Selective loss of CXCL12 (top) and decreased levels of VEGF (middle) and FGF-2 (bottom)

155 in eKO mice. Magnification x20, scale bar $200 \mu \mathrm{m}$.

156

157 
bioRxiv preprint doi: https://doi.org/10.1101/2020.05.24.113845; this version posted May 27, 2020. The copyright holder for this preprint (which was not certified by peer review) is the author/funder, who has granted bioRxiv a license to display the preprint in perpetuity. It is made available under ACC-BY-NC-ND 4.0 International license.
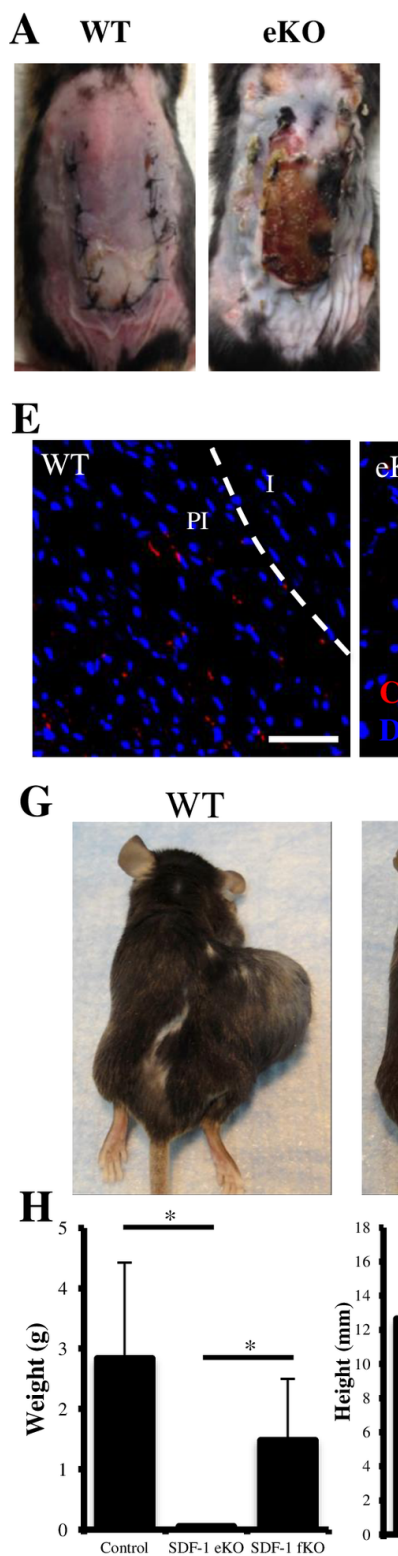

I

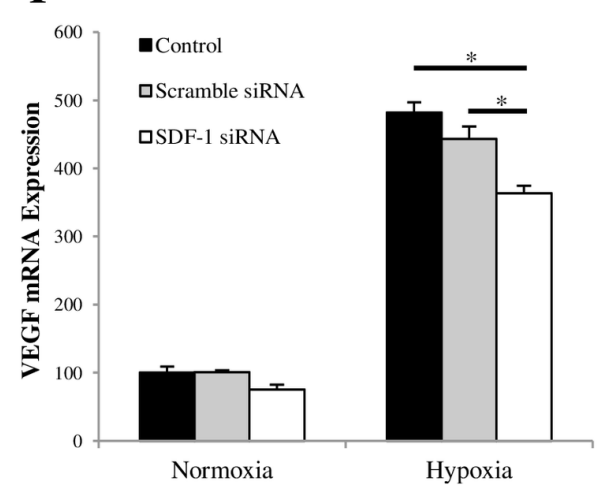

C
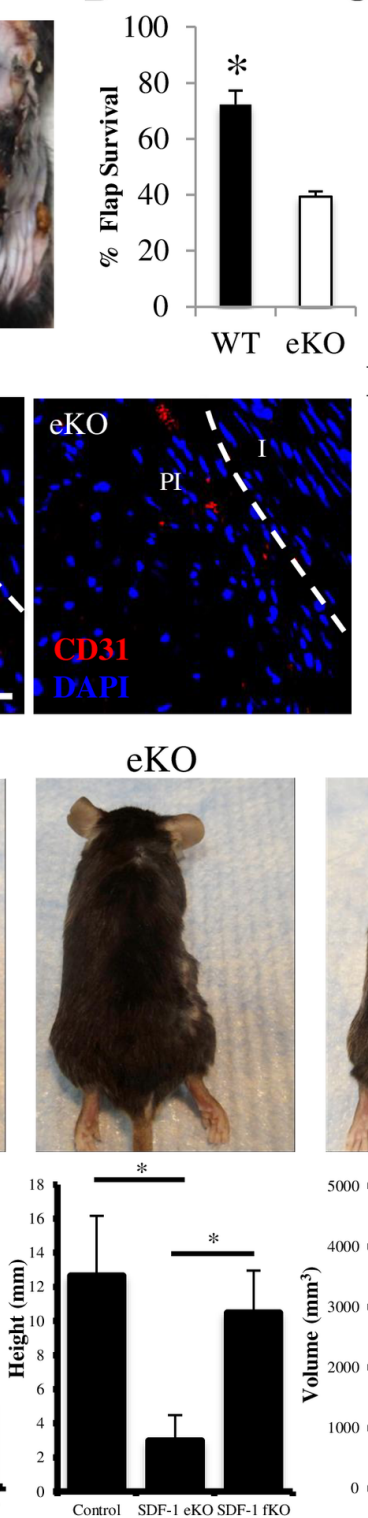

$\mathbf{J}$
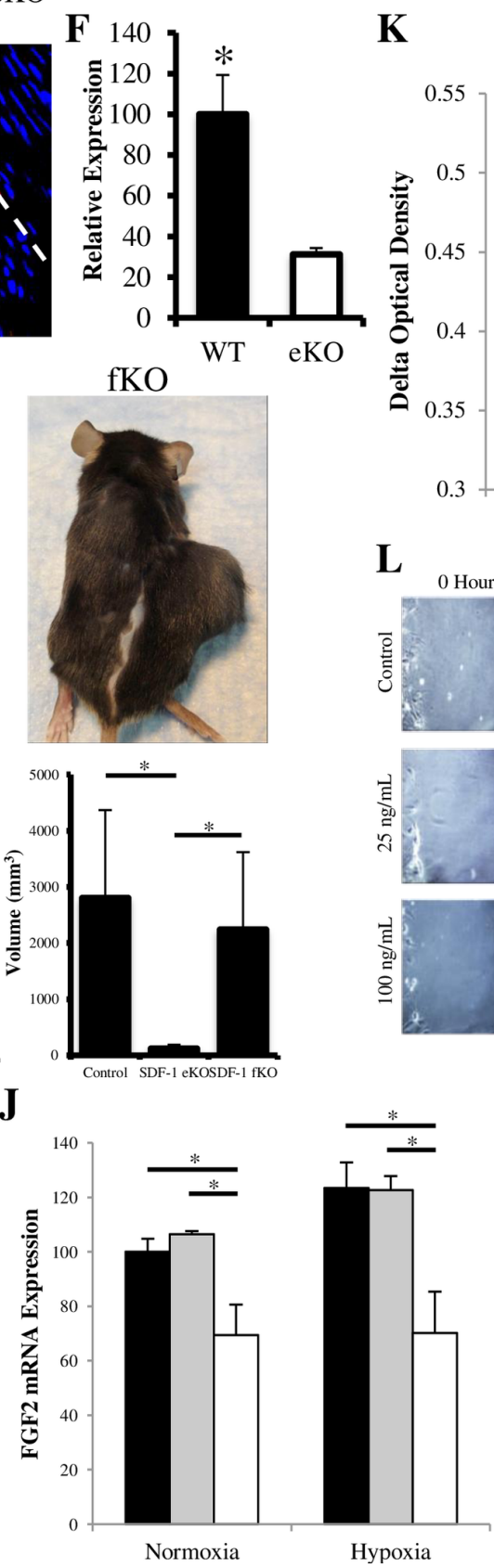

K

$\mathbf{L}$
D
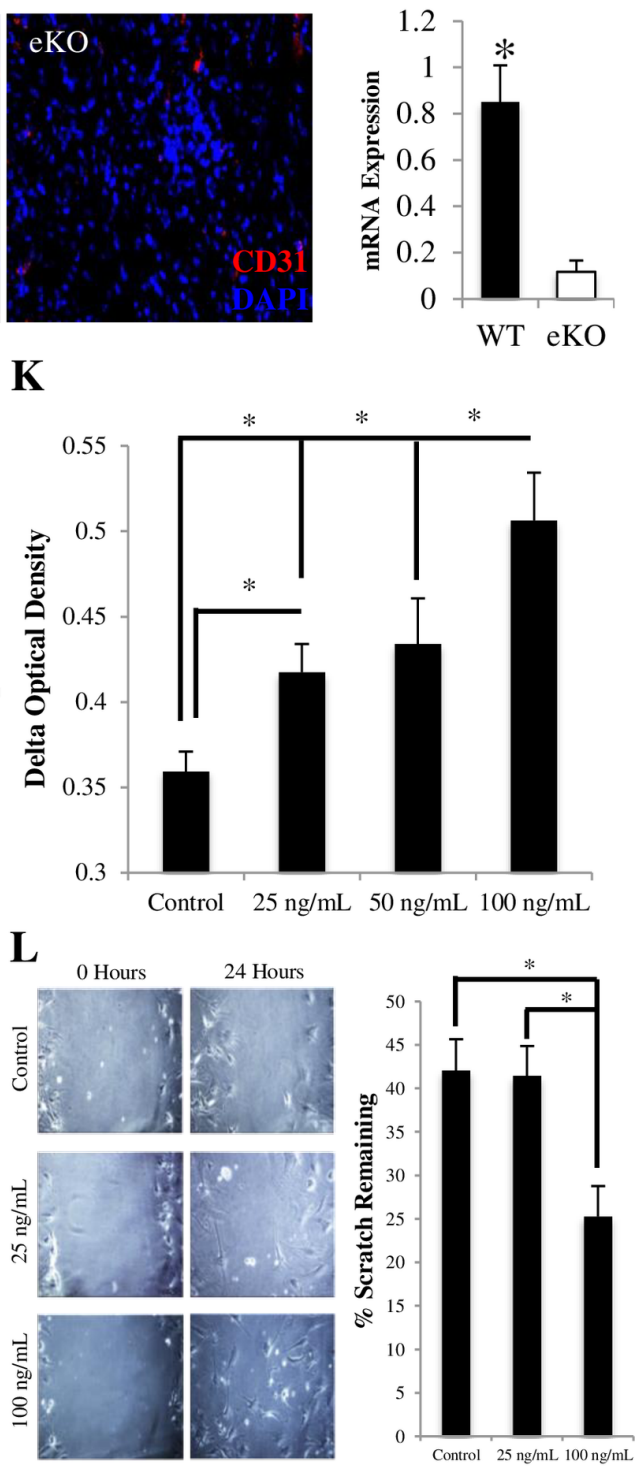

$\mathbf{M}$

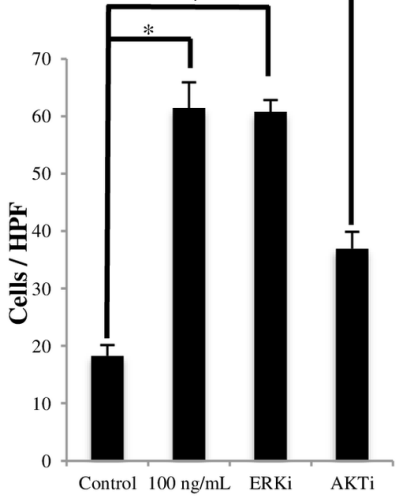


Figure 3. Endothelial CXCL12 regulates neovascularization, stroma formation, and tumor progression.

(A, B) Decreased ischemic skin flap survival in eKO mice. (C, D) Decreased vascular density in ischemic tissue of eKO mice. Images obtained with a Zeiss Axioplan 2 fluorescence microscope, magnification x20, scale bar $200 \mu \mathrm{m}$. (E, F) Decreased vascular density in peri-infarct zone of eKO myocardium. $(\mathrm{PI}=$ peri-infarct zone; $\mathrm{I}=$ infarct zone). Magnification x20, scale bar $200 \mu \mathrm{m} .(\mathrm{G}, \mathrm{H})$

166 Significantly reduced tumor burden in eKO mice. ( $(\mathrm{KO}=$ fibroblast specific CXCL12 knockout) (I, J)

167 Decreased fibroblast expression of VEGF and FGF-2 in the presence of decreased endothelial expression of CXCL12. (K, L, M) Increased fibroblast proliferation, migratory capacity, and survival 


\section{Tumor growth is dependent on host vascular endothelial CXCL12 expression}

173 Cancer cells, which typically exist in the setting of relative ischemia (Helmlinger et al., 1997) appear to rely on the stromal microenvironment for tumor growth, angiogenesis, and invasion (Li et al., 2003). In

175

particular, melanoma has been shown to rely on its surrounding stroma (Flach et al., 2011) and CXCL12, typically derived from cancer cells, has been implicated in tumor progression and survival (Teicher et al., 2010), including in B16 murine melanoma cells (Mendt et al., 2017). To determine if host endothelial CXCL12 had a role in tumor stroma formation and tumor progression, we transplanted B16 murine melanoma cells into control, eKO, and fibroblast-specific (Colla2-creER transgene) (Ubil et al., 2014; Zheng et al., 2002) CXCL12 knockout (fKO) mice. The fKO model was chosen in order to study whether stromal cells themselves produce CXCL12 in sufficient amounts to drive tumor progression, independent of endothelial cell or other circulatory sources. Tumor measurements demonstrated completely abrogated tumor growth only in eKO mice (Figure 3G, H), suggesting a pivotal role for host endothelial CXCL12 in tumor progression.

\section{Vascular endothelial CXCL12 regulates fibroblast gene expression, proliferation and migration}

The establishment of new vascularized tissue, or stroma, requires a coordinated interplay between endothelial cells and fibroblasts (Fukumura et al., 1998; Newman et al., 2011; Stratman et al., 2009). To explore the role of CXCL12 in endothelial - fibroblast cross talk, we used siRNA to target CXCL12 in human microvascular endothelial cells co-cultured with normal human dermal fibroblasts. Decreasing endothelial production of CXCL12 reduced fibroblast expression of VEGF and FGF-2 in response to hypoxia (Figure 3I, J). These data suggest that hypoxia-responsive fibroblast expression of VEGF and FGF-2, which stimulate endothelial cells to proliferate and form new vessels, is in turn reliant on vascular endothelial expression of CXCL12 and provide a possible mechanism for our earlier immunostaining 
results in injured eKO skin (Figure 2F-H). Additionally, VEGF has been shown to impart drug resistance to tumor endothelial cells within the tumor stroma (Hida et al., 2013), which suggests that endothelial CXCL12 may induce drug resistance in tumors through a paracrine mechanism. Next, we treated fibroblasts with recombinant CXCL12 and demonstrated increased proliferation and migratory capacity (Figure 3K, L). CXCL12 also enhanced the survival of fibroblasts in a low nutrient environment (Figure 3M). It has become increasingly evident that the tumor microenvironment plays a critical role in cancer progression and treatment outcomes. Collectively, these data reveal a novel mechanism by which host endothelial CXCL12 governs the formation of a critical component of this microenvironment and, therefore, tumor progression.

\section{Vascular endothelial CXCL12 recruits a unique non-inflammatory circulating cell to injured tissue}

Because the endothelium is the primary interface between the circulation and the tissue it supplies, and as endothelial cells are crucial for inflammatory cell recruitment (Lawrence et al., 1991; Möhle et al., 1998), we asked whether endothelial specific CXCL12 has a role in the recruitment of non-inflammatory circulating cells that may participate in the neovascularization of hypoxic tissue. Wild type and eKO recipient mice were parabiosed to GFP positive donor mice and cross-circulation was confirmed after 3 weeks using fluorescent imaging and FACS analysis (Figure 4A). Excisional wounds were subsequently created on the dorsum of $\mathrm{eKO}$ recipient mice and demonstrated reduced recruitment of mature hematopoietic lineage negative (Ly6C/G, CD45R, TER119, CD4, CD8, and CD11b), GFP positive cells (Figure 4B,C), which would include all types of progenitor cells and exclude inflammatory cells such as neutrophils and lymphocytes. To better characterize the progenitor cells differentially recruited to eKO and control recipient mice, we utilized microfluidic technology to apply a massively parallel single cell transcriptional analysis (SCA) (Supplementary Figure 2, Supplementary Figure 3). Partitional clustering 
revealed four transcriptionally distinct subpopulations of non-inflammatory progenitor cells in injured 219 tissue. One of these subpopulations (cluster 2) was completely absent in eKO mice, while another was 220 reduced in eKO mice. The remaining two populations were preserved across control and eKO mice (Figure 221 4D, Supplementary Figure 4, Supplementary Figure 5). The subpopulation completely absent from injured eKO tissue was defined by increased expression of genes associated with progenitor cells, such as Ckit and Mcam, and vascular genes, such as Pecam1, Flt1, Tie1, and Tek. Additionally, this population differentially expressed the cellular adhesion gene Itgb3 (Figure 4E). Pathway analysis software was used to generate a transcriptional network utilizing those genes differentially expressed in this cluster as seed genes. "Inferred" genes included those known to be implicated in cell survival (Erk1/2, Akt, Nfkb complex), neovascularization (Vegf, Pdgfb), and extracellular matrix interactions (Fak). The overall associated biological functions of this network included Cardiovascular System Development and Function, Cellular Movement, and Cell Morphology (Figure 4F). Collectively, these data indicate that endothelial CXCL12 signaling regulates the recruitment of a unique non-inflammatory circulating cell to 231 injured tissue. 
bioRxiv preprint doi: https://doi.org/10.1101/2020.05.24.113845; this version posted May 27, 2020. The copyright holder for this preprint (which was not certified by peer review) is the author/funder, who has granted bioRxiv a license to display the preprint in perpetuity. It is made available under aCC-BY-NC-ND 4.0 International license.

A

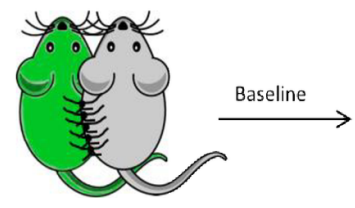

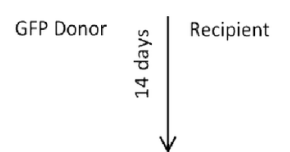
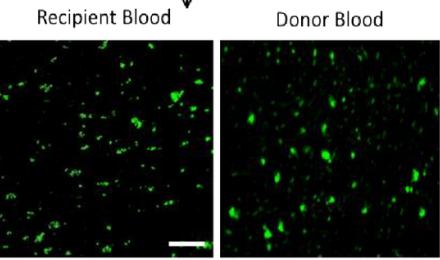

C

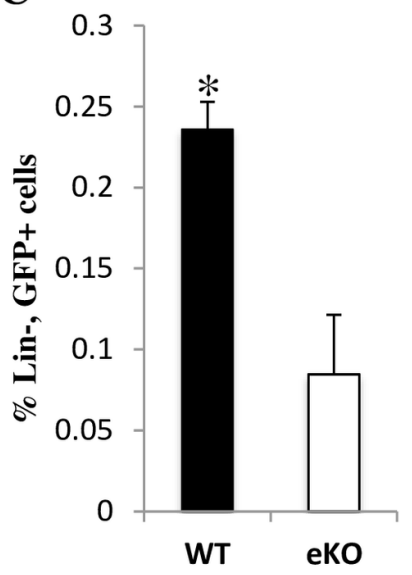

Recipient Blood
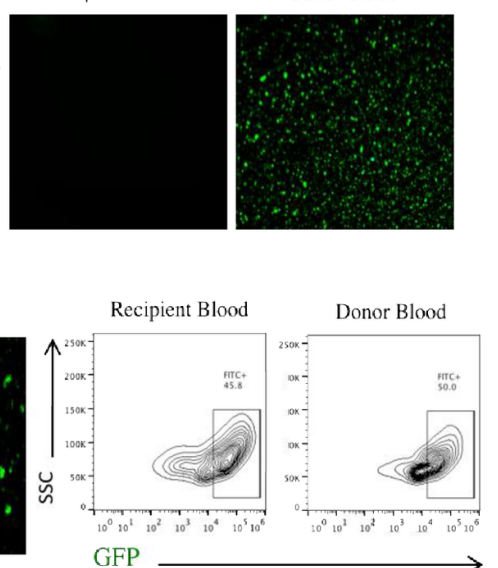

Day 0

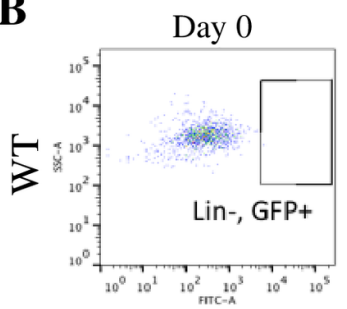

Day 0

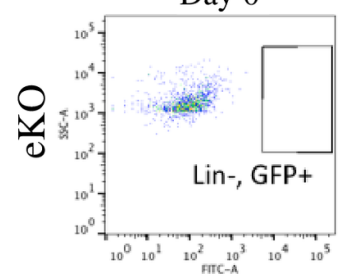

Day 7

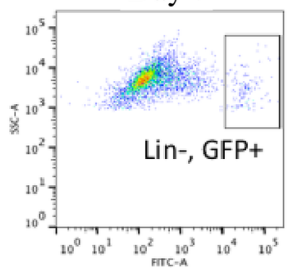

Day 7

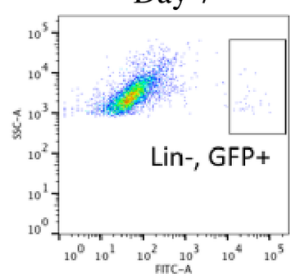

D
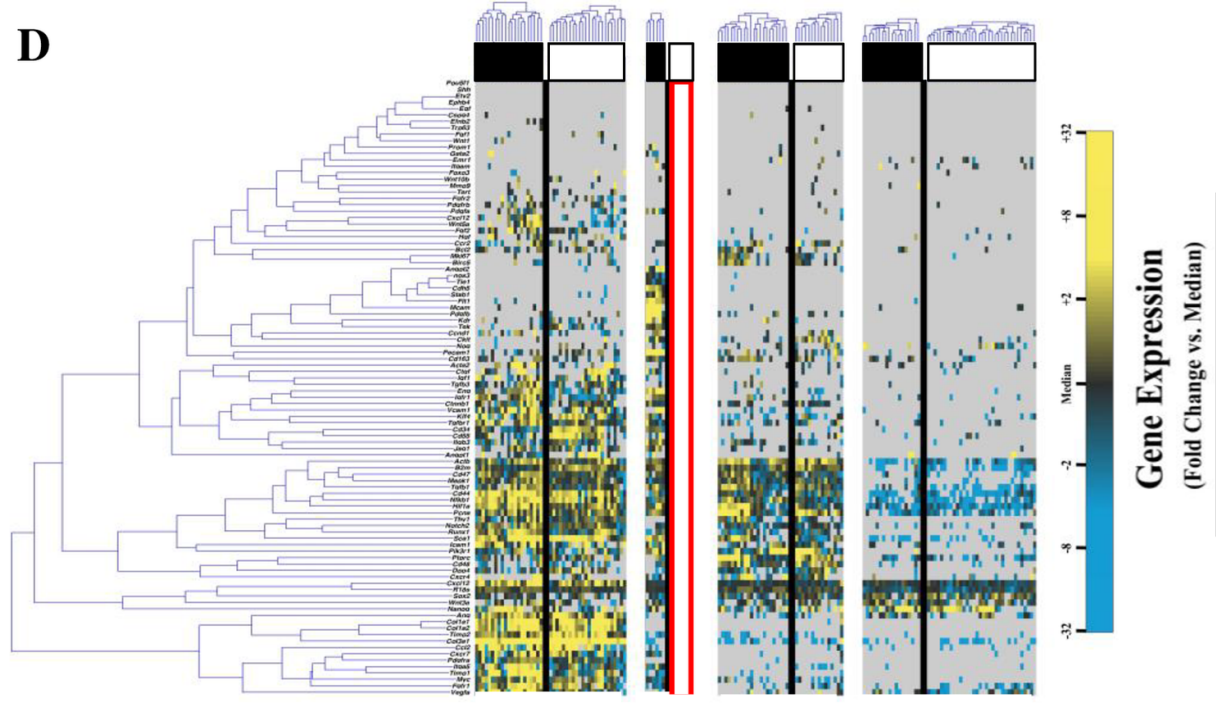

$\mathbf{E}$

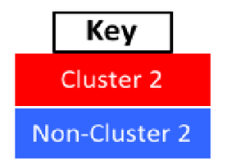

Angpt2 $\mathrm{p}<10^{-3}$

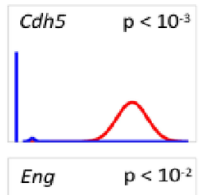

F
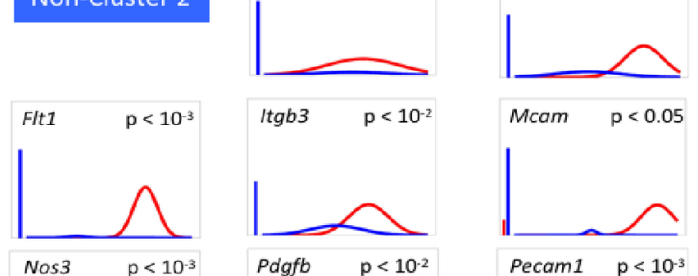

Itgb3 $\mathrm{p}<10^{-2}$
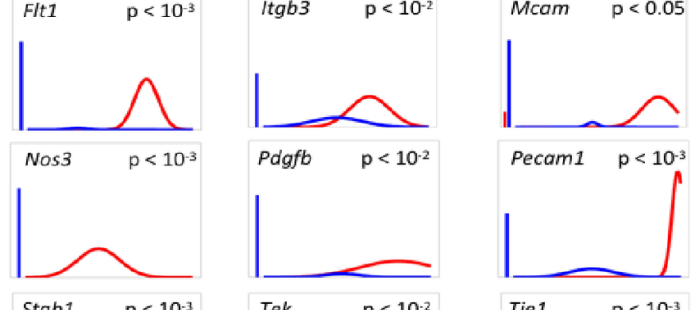

Stab1 $\mathrm{p}<10^{-3}$
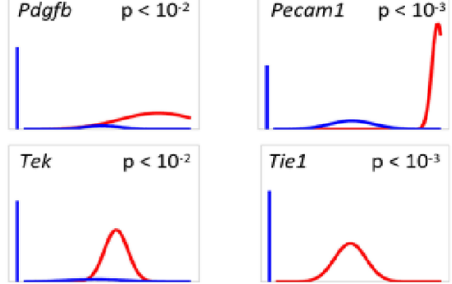
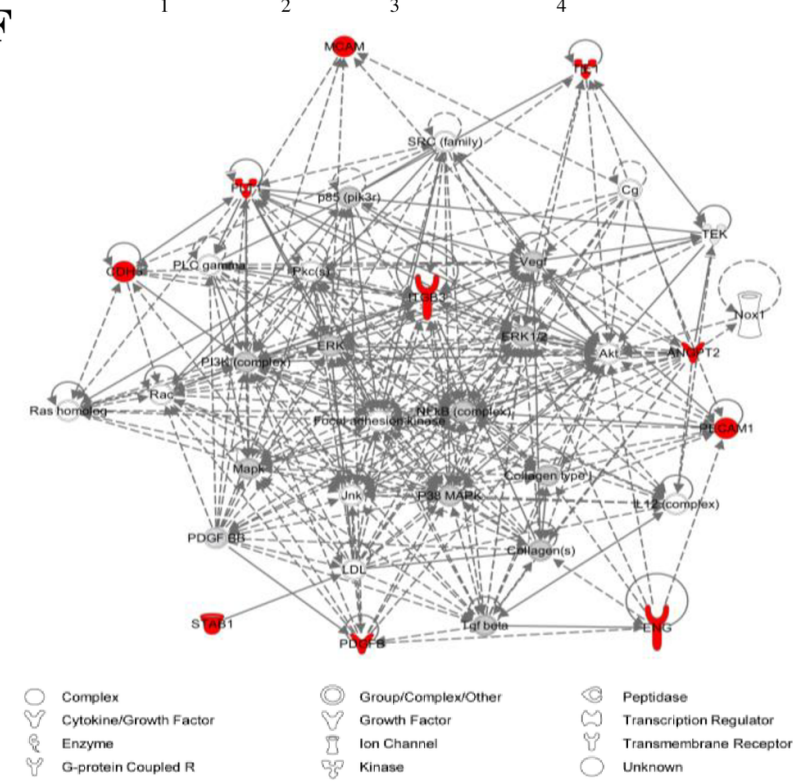
235 Figure 4. Endothelial CXCL12 regulates recruitment of progenitor cells in ischemic tissue.

236 (A) Parabiosis schema and demonstration of cross-circulation. Images obtained with a Zeiss Axioplan 2

237 fluorescence microscope, magnification x20, scale bar $200 \mu \mathrm{m}$. (B, C) Decreased recruitment of non-

238 inflammatory circulating cells to wounds of eKO mice. (D) Single-cell analysis demonstrating absence

239 of sub-population of non-inflammatory circulating cells from wounds of eKO mice. (E) Differentially

240 expressed genes defining cell population absent from eKO wounds. Left bar for each panel represents

241 fraction of cells that failed to amplify. (F) Top scoring Ingenuity Pathway Analysis (IPA)-constructed

242 transcriptome network based on population defining "seed" genes (E). Seed genes are colored in red,

243 inferred genes in grey. 


\section{Discussion}

246 We describe the differential function of CXCL12 depending on its physiological context and tissue of origin: endothelial expression does not regulate organ development or vascularization during embryogenesis, in contrast to stromal CXCL12 expression (Tachibana et al., 1998), but it does influence the expression of hypoxia-responsive, angiogenic genes and regulates the neovascular response during both the repair of injured tissue and tumor progression. Although the chemotactic effect of CXCL12 in the context of leukocytes has been investigated (Campbell et al., 1998), its physiological function and cellular source in the context of injury had not been previously elucidated. We propose that a distinct population of circulating, non-inflammatory progenitor cells that originate from the bone marrow are

Our findings extend previous work examining the relationship between tumor pathobiology and the mechanisms underlying tissue repair (tumor/wound). Targeting the tumor microenvironment is an emerging paradigm in the management of resistant tumors. Our results demonstrate that host CXCL12 critically regulates the microenvironment independent of tumor derived CXCL12, presenting a potential target for clinical therapy. However, it remains unclear why the selective inactivation of CXCL12 in endothelial cells has such profound effects on tumor growth despite expression of CXCL12 by several other cell types, including tumor endothelial cells. Our findings may also have implications for the development of personalized oncological therapies, as understanding patient-specific biological responses to cancer may be more crucial than tumor profiling. While this study does not exhaustively explore the mechanisms underlying the similar effects of endothelial CXCL12 on tumor growth and tissue repair, there is increasing evidence in the literature of the molecular and cellular similarities between wound 
bioRxiv preprint doi: https://doi.org/10.1101/2020.05.24.113845; this version posted May 27, 2020. The copyright holder for this preprint (which

was not certified by peer review) is the author/funder, who has granted bioRxiv a license to display the preprint in perpetuity. It is made available under aCC-BY-NC-ND 4.0 International license.

267 healing and tumorigenesis (Arwert et al., 2012; Flier et al., 1986; Schäfer et al., 2008). Further research 268 parsing out potential differences are likely necessary to inform the development of clinical therapies. 


\section{Materials and Methods}

\section{Mice}

All transgenic strains had been backcrossed at least ten generations onto a C57BL/6 background (Jackson Laboratories, Bar Harbor, ME). Rosa-creER, Tie2-cre(14) and Colla2-creER mice were obtained from the Jackson Laboratory. GFP positive $C 57 B L / 6-T g(C A G-E G F P) 1 O s b / J$ mice were similarly obtained from Jackson Laboratory. Mice were maintained under standard pathogen-free conditions according to methods approved by the Stanford University Administrative Panel on Laboratory Animal Care (APLAC). All animal experiments were compliant with ethical regulations and approved by the Stanford University APLAC.

\section{Generation of CXCL12 $2^{\text {loxP/loxP }}$ Mice}

A floxed allele of $\mathrm{Cxcl1} 2$ was generated by inserting LoxP sites flanking exon 2 of Cxcl12. FRT sites were inserted flanking the neomycin selection cassette (Figure 1). Generation of targeted embryonic stem cells and blastocyst injections were performed as previously described (Greenbaum et al., 2013). Excision of the neomycin cassette was accomplished through FLP-FRT recombination. Mice were genotyped using PCR primers: Cxcl12 $2^{\text {loxP }}$ forward, 5'-ACCCATAAATTGAAACATTTGG-3'; Cxcl12 $2^{\text {loxP }}$ reverse, 5'TTCTACCACCTGCAGTTTTCC-3'; Cxcl12 $2^{\text {loxP }}$ recombined, 5'-GGTAAATTTATCGAATTCCGAA$3^{\prime}$.

\section{Animal Studies}

Animal studies were performed with $n=5$ animals, and repeated at least twice, unless otherwise specified. Mice were 12-16 weeks of age at start of experiments. 


\section{Murine Excisional Wound Model}

294 Splinted excisional wounds were created as previously described (Galiano et al., 2004). Briefly, using a 6-mm biopsy punch (Integra Miltex, Plainsboro, NJ), two 6-mm full thickness wounds were created on the shaved dorsum of anesthetized mice. In parabiotic pairs, the recipient mouse was only wounded on the non-parabiosed side. A donut-shaped silicone splint (10-mm diameter) was centered on the wound and secured to the skin using an immediate-bonding adhesive (Krazy Glue; Elmer's Inc., Columbus, Ohio) and 6-0 nylon sutures (Ethicon Inc. Somerville, NJ) to prevent wound contraction. All wounds were covered using an occlusive dressing (Tegaderm; 3M, St. Paul, MN). Following surgery, the mice were placed on warming pads and allowed to fully recover from anesthesia before being returned to the institutional animal facility. Digital photographs were taken at regular intervals and wound area was measured using ImageJ software $(\mathrm{NIH})(\mathrm{n}=6$ mice). All measurements were performed by a blinded observer. Wound tissue was harvested on post-wounding day 7 and once wounds were completely healed using an $8 \mathrm{~mm}$ punch biopsy.

A reproducible model of graded soft tissue ischemia was created on the dorsum of mice as previously described (Valkenburg et al., 2018). Briefly, a full thickness (epidermis, dermis, and underlying adipose tissue) 3-sided peninsular flap $(1.25 \times 2.5 \mathrm{~cm})$ was created on the shaved dorsum. The flap was elevated

311 from the underlying muscular bed and a $0.13 \mathrm{~mm}$ thick silicone sheet was inserted to separate the skin 312 from the underlying tissue. The skin flap was sutured back into place with 6-0 nylon sutures. This model 313 creates a gradient of increasing ischemia from proximal to distal. Digital photographs were taken at regular 314 intervals and necrosed area was measured using ImageJ software (NIH) $(n=6$ mice). All measurements 315 were performed by a blinded observer. 


\section{Murine Myocardial Infarction Model}

Ligation of the mid left anterior descending (LAD) artery was performed by a single experienced surgeon (JR) as previously described (Patten et al., 1998). Infarction was confirmed by myocardial blanching and EKG changes. Animals were euthanized and hearts explanted at postoperative day $30(n=6$ mice, repeated once).

\section{Murine Parabiosis Model}

GFP positive "donor" and either control or eKO "recipient" mice were shaved and anesthetized. Parabiosis surgery was performed as previously described ( $\mathrm{n}=5$ mice analyzed) (Bunster et al., 1933; Wagers et al., 2002). Briefly, the corresponding flanks of mice were shaved and disinfected with betadine solution and $70 \%$ ethanol. Matching skin incisions were made from the olecranon to the knee joint of each mouse. The skin edges were undermined to create about $1 \mathrm{~cm}$ of free skin. 6-0 nylon sutures were used to approximate the dorsal and ventral skin. The skin was over-sewn to protect the suture line. Mice were allowed to recover as described above. Buprenorphine was used for analgesia by subcutaneous injection every 8-12 hours for 48 hours post operation. After three weeks, cross-circulation was confirmed using fluorescent microscopy and FACS analysis (Figure 4A).

\section{Murine Tumor Model}

A $1 \mathrm{~cm}$ incision was created on the right flank of shaved and anesthetized control, eKO, and fKO mice. A $1 \times 1 \mathrm{~cm}$ subcutaneous pocket was created and a hydrogel (Wong et al., 2010) seeded with $2.5 \times 10^{5}$ B16F10 melanoma cells (ATCC CRL-6475) was implanted and the incision closed with 6-0 nylon suture. Measurements for length, width, and height were taken with a digital caliper and tumor volume was calculated using the formula: $\mathrm{V}=0.5 \times(\mathrm{L} \times \mathrm{W} \times \mathrm{H})$, where $\mathrm{V}$ is tumor volume, $\mathrm{L}$ is length, $\mathrm{W}$ is width, 
and $\mathrm{H}$ is height. Tumor sizes were measured by the same, blinded observer every other day until mice were euthanized at 4 weeks.

\section{Blood and Skin Analysis}

Mononuclear cells from blood were obtained from the buffy coat layer following Ficol-Paque density centrifugation (Jaatinen et al., 2007). Skin samples, including wounded tissue and ischemic skin, were digested and cells isolated as previously described (Suga et al., 2014).

\section{Histology and Tissue Analysis}

For fixation, tissues were placed in $2 \%$ paraformaldehyde for $12-16$ hours at $4^{\circ} \mathrm{C}$. Samples were prepared for embedding by soaking in $30 \%$ sucrose in PBS at $4^{\circ} \mathrm{C}$ for 24 hours. Samples were removed from the sucrose solution and tissue blocks were prepared by embedding in Tissue Tek O.C.T (Sakura Finetek) on dry ice. Frozen blocks were mounted on a MicroM HM550 cryostat (MICROM International GmbH) and 5-8 micron thick sections were transferred to Superfrost/Plus adhesive slides (Fisher \& Company, Inc.).

\section{Immunohistochemistry}

For hematoxylin and eosin staining, standardized protocols were used with no modifications. Sections were visualized using Leica DM4000B microscope (Leica Microsystems). Immunostaining on frozen sections was performed using the following primary antibodies: CD31 (Abcam 28364), SDF-1 (Abcam 25117), VEGF (Abcam 52917), and FGF-2 (Abcam 8880). Briefly, slides were fixed in cold acetone (-

$20^{\circ} \mathrm{C}$ ), and then blocked for 1 hour in $5 \%$ goat serum at room temperature followed by incubation with primary antibody for $12-16$ hours at $4^{\circ} \mathrm{C}$. Slides were then incubated for 1 hour with goat anti-rabbit Alexa Fluor 488 conjugate (Invitrogen A-11034) or 594 conjugate (Invitrogen A-11037). A Zeiss Axioplan 2 
362 fluorescence microscope was used to image the slides (Carl Zeiss, Inc., Thornwood, NY). Quantification 363 of fluorescence was performed by a blinded observer using ImageJ software (NIH).

\section{Flow Cytometry}

All flow cytometry analysis was performed on dissociated wound tissue or blood. Cells were stained by standard protocols with the following fluorescently conjugated antibodies (eBiosciences unless otherwise noted). Lineage analysis was assessed using R-Phycoerythrin (PE)-Cy5-conjugated Ly6C/G (RB6-8C5, Gr-1, myeloid), CD45R (RA3-6B2, B220, B lymphocytes), TER119, CD4, CD8, and CD11b. Cells not stained with these antibodies were incubated with the proper isotype controls or left unstained. Cells were resuspended in FACS buffer and DAPI prior to FACS analysis on a FACSAria II. At least 50,000 events were recorded per sample. Data were analyzed using FlowJo digital fluorescence-activated cell sorting software by a single blinded evaluator (Tree Star Inc, Ashland, OR).

\section{Quantitative Reverse-Transcription PCR}

RNA was isolated using an RNeasy Mini Kit (Qiagen, Hilden, Germany) according to the manufacturer's instructions. Reverse transcription was performed with 500 ng RNA using the SuperScript III First-Strand Synthesis System (Invitrogen, Carlsbad, CA). qRT-PCR was carried out using TaqMan ${ }^{\circledR}$ Assays-onrelative values. 


\section{In Vitro Assays}

386 Human dermal fibroblasts (HdFbs) (Life Technologies C0135C) and human dermal microvascular endothelial cells (HdMVECs) (Life Technologies C01125PA) were purchased and used for in vitro assays. All assays were conducted in triplicate unless otherwise stated.

\section{Co-Culture}

Indirect co-culture experiments were performed using 6-well plates and $0.4 \mu \mathrm{M}$ pore trans-well inserts.

$\mathrm{HdFb}$ were seeded in the upper chamber and HdMVECs were seeded in the lower chamber. si-CXCL12 and scrambled-siRNA were purchased form Life Technologies. HMVECs were transfected using Lipofectamine RNAiMAX Reagent (Life Technologies) according to the manufacturer's protocol before co-culture with $\mathrm{HdFb}$ in normoxia and hypoxia as previously described (Ceradini et al., n.d.).

\section{Proliferation}

398 Human dermal fibroblasts were plated in 96-well cell-culture plates, 2500 cells/well, in $150 \mu \mathrm{L}$ of medium 399 with 1\% FBS. After 24 hours, fresh media with 1\% FBS alone or with varying concentrations of recombinant CXCL12 (25, 50, and $100 \mathrm{ng} / \mathrm{mL})$ were added and after an additional 6 hours BrdU was added and a cell proliferation assay was performed according to the manufacturer's instructions (Roche Applied Sciences).

\section{Migration}

405 Scratch assay was performed as previously described (Wang et al., 2018) on HdFb cultured in 24-well 406 plates with culture medium containing 1\% FBS alone or with varying concentrations of recombinant 


\section{Survival}

$\mathrm{HdFb}$ were cultured until $90 \%$ confluent in 24 -well plates. They were then placed in culture medium containing 1\% FBS for 24 hours then cultured in medium containing $0.5 \%$ FBS alone, $100 \mathrm{ng} / \mathrm{mL}$ recombinant CXCL12, 100 ng/mL recombinant CXCL12 + U0126 (Cell Signaling Technology), or 100 ng/mL recombinant CXCL12 + LY294002 (Cell Signaling Technology). After 72 hours, images of 5 HPFs/well were captured and recorded under phase contrast microscopy and manual cell counts were performed by a blinded observer.

\section{Microfluidic Single-Cell Gene Expression Analysis}

Gene lists were collected from a literature search. Single cell reverse transcription and low cycle preamplification were performed as previously described (Glotzbach et al., 2011; Januszyk et al., 2014). Briefly, wound lysate cell suspensions were sorted from Tie-2 $2^{\text {Cre }} / C X C L 12^{\text {loxP/loxP }}$ and $C X C L 12^{\text {loxP } / l o x P}$ transgenic mice as single progenitor cells into each well of a 96-well plate using a Becton Dickinson FACSAria flow cytometer (Franklin Lakes, NJ) into $6 \mu$ of lysis buffer and SUPERase-In RNAse inhibitor (Applied Biosystems, Foster City, CA) (N=5 mice). Live/dead gating was performed based on DAPI exclusion. Progenitor cells were defined as previously described. Reverse transcription and low cycle pre-amplification were performed using Cells Direct (Invitrogen) with Taqman assay primer sets (Applied Biosystems) as per the manufacturers specifications. Exon-spanning primers were used where possible to avoid amplification of genomic background. cDNA was loaded onto 96.96 Dynamic Arrays (Fluidigm, South San Francisco, CA) for qPCR amplification using Universal PCR Master Mix (Applied Biosystems) with a uniquely compiled Taqman assay primer set (Supplementary Table 1) as previously described (Glotzbach et al., 2011). 


\section{Statistical Analysis}

432 For comparison between two groups, students t-tests were used with a P-value $<0.05$ considered statistically significant. Analysis of single cell data was performed as described previously (Glotzbach et al., 2011; Januszyk et al., 2014; Levi et al., 2011). Briefly, data from all samples were normalized relative to the pooled median expression for each gene and converted to base 2 logarithms. Absolute bounds (+/5 cycle thresholds from the median or 32-fold increases/decreases in expression) were set, and nonexpressers were assigned to this floor. Clustergrams were then generated using hierarchical clustering (with a 'complete' linkage function and Euclidean distance metric) to facilitate data visualization

To detect overlapping patterns within the single cell transcriptional data, k-means clustering was employed using a standard Euclidean distance metric. Accordingly, each cell was assigned membership to a specific cluster as dictated by similarities in expression profiles (minimizing the within-cluster sum of square distances) in MATLAB. Optimally partitioned clusters were then sub-grouped using hierarchical clustering to facilitate visualization of data patterning (Fukumura et al., 1998; Newman et al., 2011). Nonparametric, two-sample Kolmogorov-Smirnov (K-S) tests were used to identify those genes with expression patterns that differed significantly between population clusters and/or groups, following Bonferroni correction for multiple samples using a strict cutoff of $p<0.05$. For subgroup comparisons, the empirical distribution of cells from each cluster was evaluated against that of the remaining cells in the experiment. Ingenuity Pathway Analysis (IPA, Ingenuity Systems, Redwood City, CA) was used to construct transcriptome networks based on genes that were significantly increased within clusters (including both direct and indirect relationships). 
bioRxiv preprint doi: https://doi.org/10.1101/2020.05.24.113845; this version posted May 27, 2020. The copyright holder for this preprint (which

was not certified by peer review) is the author/funder, who has granted bioRxiv a license to display the preprint in perpetuity. It is made available under aCC-BY-NC-ND 4.0 International license.

\section{Data Sharing Statement}

455 Original data may be obtained by e-mail request to the corresponding author. Single cell transcriptional

456 data is available at GEO under accession number GSE146529.

457

458

459

460

461

462

463

464

465

466

467

468

\section{Acknowledgments}

We thank Theresa Carlomagno for administrative support and Yujin Park for help with tissue processing.

Competing interests: The authors declare no conflicts of interest. 


\section{References}

Arwert, E. N., Hoste, E., \& Watt, F. M. (2012). Epithelial stem cells, wound healing and cancer. Nature Reviews. Cancer, 12(3), 170-180. doi: 10.1038/nrc3217

Brem, H., \& Tomic-Canic, M. (2007). Cellular and molecular basis of wound healing in diabetes. The Journal of Clinical Investigation, 117(5), 1219-1222. doi: 10.1172/JCI32169

Bunster, E., \& Meyer, R. K. (1933). An improved method of parabiosis. The Anatomical Record, 57(4), 339-343. doi: 10.1002/ar.1090570404

Campbell, J. J., Hedrick, J., Zlotnik, A., Siani, M. A., Thompson, D. A., \& Butcher, E. C. (1998). Chemokines and the arrest of lymphocytes rolling under flow conditions. Science (New York, N.Y.), 279(5349), 381-384. doi: 10.1126/science.279.5349.381

Carmeliet, P., \& Jain, R. K. (2011). Molecular mechanisms and clinical applications of angiogenesis. Nature, 473(7347), 298-307. doi: 10.1038/nature10144

Ceradini, D. J., Kulkarni, A. R., Callaghan, M. J., Tepper, O. M., Bastidas, N., Kleinman, M. E., Capla, J. M., Galiano, R. D., Levine, J. P., \& Gurtner, G. C. (n.d.). Progenitor cell trafficking is regulated by hypoxic gradients through HIF-1 induction of SDF-1. Nature Medicine, 10(8), 858864.

Chen, J., Zhang, Z. G., Li, Y., Wang, L., Xu, Y. X., Gautam, S. C., Lu, M., Zhu, Z., \& Chopp, M. (2003). Intravenous administration of human bone marrow stromal cells induces angiogenesis in the ischemic boundary zone after stroke in rats. Circulation Research, 92(6), 692-699. doi: 10.1161/01.RES.0000063425.51108.8D

Ding, L., \& Morrison, S. J. (2013). Haematopoietic stem cells and early lymphoid progenitors occupy distinct bone marrow niches. Nature, 495(7440), 231-235. doi: 10.1038/nature11885 
Feig, C., Jones, J. O., Kraman, M., Wells, R. J. B., Deonarine, A., Chan, D. S., Connell, C. M., Roberts, E. W., Zhao, Q., Caballero, O. L., Teichmann, S. A., Janowitz, T., Jodrell, D. I., Tuveson, D. A., \& Fearon, D. T. (2013). Targeting CXCL12 from FAP-expressing carcinoma-associated fibroblasts synergizes with anti-PD-L1 immunotherapy in pancreatic cancer. Proceedings of the National Academy of Sciences of the United States of America, 110(50), 20212-20217. doi: 10.1073/pnas. 1320318110

Flach, E. H., Rebecca, V. W., Herlyn, M., Smalley, K. S. M., \& Anderson, A. R. A. (2011). Fibroblasts contribute to melanoma tumor growth and drug resistance. Molecular Pharmaceutics, 8(6), 2039-2049. doi: 10.1021/mp200421k

Flier, J. S., Underhill, L. H., \& Dvorak, H. F. (1986). Tumors: Wounds That Do Not Heal. New England Journal of Medicine, 315(26), 1650-1659. doi: 10.1056/NEJM198612253152606

Fukumura, D., Xavier, R., Sugiura, T., Chen, Y., Park, E. C., Lu, N., Selig, M., Nielsen, G., Taksir, T., Jain, R. K., \& Seed, B. (1998). Tumor induction of VEGF promoter activity in stromal cells. Cell, 94(6), 715-725. doi: 10.1016/s0092-8674(00)81731-6

Galiano, R. D., Michaels, V., Dobryansky, M., Levine, J. P., Gurtner, G. C., \& others. (2004). Quantitative and reproducible murine model of excisional wound healing. Wound Repair and Regeneration, 12(4), 485-492.

Glotzbach, J. P., Januszyk, M., Vial, I. N., Wong, V. W., Gelbard, A., Kalisky, T., Thangarajah, H., Longaker, M. T., Quake, S. R., Chu, G., \& Gurtner, G. C. (2011). An Information Theoretic, Microfluidic-Based Single Cell Analysis Permits Identification of Subpopulations among Putatively Homogeneous Stem Cells. PLOS One, 6(6), e21211. doi: 10.1371/journal.pone.0021211 
Greenbaum, A., Hsu, Y.-M. S., Day, R. B., Schuettpelz, L. G., Christopher, M. J., Borgerding, J. N., Nagasawa, T., \& Link, D. C. (2013). CXCL12 in early mesenchymal progenitors is required for haematopoietic stem-cell maintenance. Nature, 495(7440), 227-230. doi: 10.1038/nature11926

Hanahan, D., \& Weinberg, R. A. (2011). Hallmarks of cancer: the next generation. Cell, 144(5), 646674. doi: 10.1016/j.cell.2011.02.013

Helmlinger, G., Yuan, F., Dellian, M., \& Jain, R. K. (1997). Interstitial pH and pO2 gradients in solid tumors in vivo: high-resolution measurements reveal a lack of correlation. Nature Medicine, 3(2), 177-182. doi: 10.1038/nm0297-177

Hida, K., Akiyama, K., Ohga, N., Maishi, N., \& Hida, Y. (2013). Tumour endothelial cells acquire drug resistance in a tumour microenvironment. Journal of Biochemistry, 153(3), 243-249. doi: $10.1093 / \mathrm{jb} / \mathrm{mvs} 152$

Jaatinen, T., \& Laine, J. (2007). Isolation of mononuclear cells from human cord blood by Ficoll-Paque density gradient. Current Protocols in Stem Cell Biology, Chapter 2, Unit 2A.1. doi: $10.1002 / 9780470151808 . s c 02 \mathrm{a} 01 \mathrm{~s} 1$

Januszyk, M., Sorkin, M., Glotzbach, J. P., Vial, I. N., Maan, Z., Rennert, R. C., Duscher, D., Thangarajah, H., Longaker, M. T., Butte, A. J., \& Gurtner, G. C. (2014). Diabetes Irreversibly Depletes Bone Marrow-Derived Mesenchymal Progenitor Cell Subpopulations. Diabetes. doi: $10.2337 / \mathrm{db} 13-1366$

Kisanuki, Y. Y., Hammer, R. E., Miyazaki, J., Williams, S. C., Richardson, J. A., \& Yanagisawa, M. (2001). Tie2-Cre transgenic mice: a new model for endothelial cell-lineage analysis in vivo. Developmental Biology, 230(2), 230-242. doi: 10.1006/dbio.2000.0106 
Lawrence, M. B., \& Springer, T. A. (1991). Leukocytes roll on a selectin at physiologic flow rates: distinction from and prerequisite for adhesion through integrins. Cell, 65(5), 859-873. doi: 10.1016/0092-8674(91)90393-d

Levi, B., Wan, D. C., Glotzbach, J. P., Hyun, J., Januszyk, M., Montoro, D., Sorkin, M., James, A. W., Nelson, E. R., Li, S., Quarto, N., Lee, M., Gurtner, G. C., \& Longaker, M. T. (2011). CD105 protein depletion enhances human adipose-derived stromal cell osteogenesis through reduction of transforming growth factor $\beta 1$ (TGF- $\beta 1$ ) signaling. The Journal of Biological Chemistry, 286(45), 39497-39509. doi: 10.1074/jbc.M111.256529

Li, G., Satyamoorthy, K., Meier, F., Berking, C., Bogenrieder, T., \& Herlyn, M. (2003). Function and regulation of melanoma-stromal fibroblast interactions: when seeds meet soil. Oncogene, 22(20), 3162-3171. doi: 10.1038/sj.onc.1206455

Mendt, M., \& Cardier, J. E. (2017). Activation of the CXCR4 chemokine receptor enhances biological functions associated with B16 melanoma liver metastasis. Melanoma Research, 27(4), 300-308. doi: 10.1097/CMR.0000000000000346

Möhle, R., Rafii, S., \& Moore, M. A. (1998). The role of endothelium in the regulation of hematopoietic stem cell migration. Stem Cells (Dayton, Ohio), 16 Suppl 1, 159-165. doi: $10.1002 /$ stem.5530160819

Nagasawa, T., Hirota, S., Tachibana, K., Takakura, N., Nishikawa, S., Kitamura, Y., Yoshida, N., Kikutani, H., \& Kishimoto, T. (1996). Defects of B-cell lymphopoiesis and bone-marrow myelopoiesis in mice lacking the CXC chemokine PBSF/SDF-1. Nature, 382(6592), 635-638. doi: $10.1038 / 382635 \mathrm{a} 0$

Newman, A. C., Nakatsu, M. N., Chou, W., Gershon, P. D., \& Hughes, C. C. W. (2011). The requirement for fibroblasts in angiogenesis: fibroblast-derived matrix proteins are essential for 
endothelial cell lumen formation. Molecular Biology of the Cell, 22(20), 3791-3800. doi: 10.1091/mbc.E11-05-0393

Orimo, A., Gupta, P. B., Sgroi, D. C., Arenzana-Seisdedos, F., Delaunay, T., Naeem, R., Carey, V. J., Richardson, A. L., \& Weinberg, R. A. (2005). Stromal fibroblasts present in invasive human breast carcinomas promote tumor growth and angiogenesis through elevated SDF-1/CXCL12 secretion. Cell, 121(3), 335-348. doi: 10.1016/j.cell.2005.02.034

Patten, R. D., Aronovitz, M. J., Deras-Mejia, L., Pandian, N. G., Hanak, G. G., Smith, J. J., Mendelsohn, M. E., \& Konstam, M. A. (1998). Ventricular remodeling in a mouse model of myocardial infarction. American Journal of Physiology-Heart and Circulatory Physiology, 274(5), H1812H1820. doi: 10.1152/ajpheart.1998.274.5.H1812

Schäfer, M., \& Werner, S. (2008). Cancer as an overhealing wound: an old hypothesis revisited. Nature Reviews. Molecular Cell Biology, 9(8), 628-638. doi: 10.1038/nrm2455

Stratman, A. N., Malotte, K. M., Mahan, R. D., Davis, M. J., \& Davis, G. E. (2009). Pericyte recruitment during vasculogenic tube assembly stimulates endothelial basement membrane matrix formation. Blood, 114(24), 5091-5101. doi: 10.1182/blood-2009-05-222364

Suga, H., Rennert, R. C., Rodrigues, M., Sorkin, M., Glotzbach, J. P., Januszyk, M., Fujiwara, T., Longaker, M. T., \& Gurtner, G. C. (2014). Tracking the Elusive Fibrocyte: Identification and Characterization of Collagen-Producing Hematopoietic Lineage Cells During Murine Wound Healing: Tracking Fibrocytes Without Surface Markers. Stem Cells, 32(5), 1347-1360. doi: $10.1002 /$ stem. 1648

Tachibana, K., Hirota, S., Iizasa, H., Yoshida, H., Kawabata, K., Kataoka, Y., Kitamura, Y., Matsushima, K., Yoshida, N., Nishikawa, S., Kishimoto, T., \& Nagasawa, T. (1998). The 
chemokine receptor CXCR4 is essential for vascularization of the gastrointestinal tract. Nature, 393(6685), 591-594. doi: 10.1038/31261

Teicher, B. A., \& Fricker, S. P. (2010). CXCL12 (SDF-1)/CXCR4 pathway in cancer. Clinical Cancer Research: An Official Journal of the American Association for Cancer Research, 16(11), 29272931. doi: 10.1158/1078-0432.CCR-09-2329

Ubil, E., Duan, J., Pillai, I. C. L., Rosa-Garrido, M., Wu, Y., Bargiacchi, F., Lu, Y., Stanbouly, S., Huang, J., Rojas, M., Vondriska, T. M., Stefani, E., \& Deb, A. (2014). Mesenchymal-endothelial transition contributes to cardiac neovascularization. Nature, 514(7524), 585-590. doi: 10.1038 /nature13839

Valkenburg, K. C., de Groot, A. E., \& Pienta, K. J. (2018). Targeting the tumour stroma to improve cancer therapy. Nature Reviews. Clinical Oncology, 15(6), 366-381. doi: 10.1038/s41571-0180007-1

Wagers, A. J., Sherwood, R. I., Christensen, J. L., \& Weissman, I. L. (2002). Little evidence for developmental plasticity of adult hematopoietic stem cells. Science (New York, N.Y.), 297(5590), 2256-2259. doi: 10.1126/science. 1074807

Wang, Y., Zheng, J., Han, Y., Zhang, Y., Su, L., Hu, D., \& Fu, X. (2018). JAM-A knockdown accelerates the proliferation and migration of human keratinocytes, and improves wound healing in rats via FAK/Erk signaling. Cell Death \& Disease, 9(9), 848. doi: 10.1038/s41419-018-0941$\mathrm{y}$

Wong, V. W., Rustad, K. C., Galvez, M. G., Neofytou, E., Glotzbach, J. P., Januszyk, M., Major, M. R., Sorkin, M., Longaker, M. T., Rajadas, J., \& others. (2010). Engineered pullulan-collagen composite dermal hydrogels improve early cutaneous wound healing. Tissue Engineering Part A, 17(5-6), 631-644. 
bioRxiv preprint doi: https://doi.org/10.1101/2020.05.24.113845; this version posted May 27, 2020. The copyright holder for this preprint (which

was not certified by peer review) is the author/funder, who has granted bioRxiv a license to display the preprint in perpetuity. It is made available under aCC-BY-NC-ND 4.0 International license.

603 Zheng, B., Zhang, Z., Black, C. M., de Crombrugghe, B., \& Denton, C. P. (2002). Ligand-dependent 604 genetic recombination in fibroblasts : a potentially powerful technique for investigating gene 605 function in fibrosis. The American Journal of Pathology, 160(5), 1609-1617. doi:

606 10.1016/S0002-9440(10)61108-X

607 